\title{
Public Welfare Medical Care
}

\section{LUCILLE M. SMITH}

$\mathrm{T}$ HE NEW JERSEY COMMISSION to Study the Administration of Public Medical Care, created in 1956, has completed and published its report (1). The commission has invited me to present a backdrop for a discussion of its report.

Let me begin by presenting some facts for the Nation as a whole. In March 1959, payments made to suppliers for medical service for recipients of all five categories of public assistance amounted to approximately $\$ 37$ million, representing an annual rate of about $\$ 446$ million (2). The number of persons receiving assistance in that month was 6.3 million.

Of these payments, 53 percent were made in behalf of old-age assistance recipients. In the four federally aided categories, additional amounts were provided in some States in the form of money payments to enable recipients to purchase medical care, probably more than $\$ 100$ million during the year.

Let us, for purposes of perspective, contrast these figures with those revealed in the first national study of welfare medical programs in 1934 under the Federal Emergency Relief Administration (3). In March and April of that year, 17 million persons were "on relief." Expenditures for medical care were $\$ 1,700,000$, or 10 cents per person per month. This amount represented from 2.5 to 3.7 percent of all expenditures for relief. In March 1959 the monthly per capita figure was $\$ 5.93$ and medical expenditures represented 12 percent of all assistance costs.

\section{Increase in Complexity}

These figures reflect not only the general increase in medical care costs but a complex of factors: more use of hospital and nursing home care today than 25 years ago, more older people in the population, more disabled persons surviving to require long-term care, improved quality of care, and wider recognition of the importance of health services. To fully understand what the commission expects of welfare departments requires recognition of these changes and of experiments and emerging trends in new ways to organize health services.

New Jersey was 1 of 26 States which had a successful program under the Federal Emergency Relief Administration. It was statewide except for Hudson County, which provided care through its public hospital and outpatient department. 'The New Jersey program had a professional advisory committee, a full-time medical director who served without compensation, and detailed policies and procedures, including fee schedules. Although Federal funds were not then available for hospitalization, New Jersey, like six other States, met these costs from State or local funds.

In a sense, those of us who knew the Federal Emergency Relief Administration feel a nostalgia for the days when there were no categories, no complicated eligibility conditions, and there was only one public welfare medical care program. Although we can't turn the clock back, that early experience confirms the soundness of many of the commission's conclusions and recommendations which are consistent with that successful experience.

It is an understatement to say it will be more

Mrs. Smith is chief of the Health Services Organization Branch, Division of Public Health Methods, Public Health Service. The paper presents the substance of a speech delivered by Mrs. Smith during the 58th annual conference of the New Jersey Welfare Council, November 18, 1959, in Atlantic City, N.J. 
difficult to have a successful medical care program in 1960 than it was in 1934. But having been successful once, I am sure New Jersey will be again.

\section{Patterns of Administration}

To return to the present era, let us examine the variety of ways in which public welfare medical programs are administered. As of the most recent count, 38 States make vendor payments for some medical care services.

The variation in scope of services ranges from a comprehensive program covering preventive, palliative, and restorative services of all kinds to a program which only purchases drugs. In a sense, therefore, it is a fiction to say that 38 States have a medical care program. Without sufficient scope in the services included, quality of care is not available.

In two States, Hawaii and Maryland, the public health department acts as agent for the State public welfare department. In one State, the department purchases services by contract with the Blue Cross organization which receives and pays bills for certain services on a cost-plus basis in old-age assistance. In the same State, in aid to dependent children and aid to the blind programs, recipients are given Blue Cross and Blue Shield coverage on a prepaid insurance basis. In another State, the State medical society administers the program for the welfare department. In still another, the State pharmaceutical association acts as agent of the welfare department for the purchase of drugs, and the agency itself purchases all other services. In another State, the physicians' services organization has contracted to administer the plan for the State public welfare department. Thus a few States have moved to transfer partial responsibility for medical assistance to official or nonofficial agencies concerned with the purchase of medical care. The bulk of the public welfare agencies, however, are administering the program themselves, often with little relationship to other agencies which also carry medical care responsibilities.

\section{A Series of Paradoxes}

This is one of the many paradoxes in public welfare today. ILet's look at some of them.
"Do-it-yourself" has become a popular slogan in recent years for homeowners, but for public welfare administrators it is a dangerous practice. The State medical and dental societies, the State health department, the hospital association, and other health-oriented organizations have a vital role to play in the public welfare medical care program in every State.

Another paradox is the physicians role in public assistance.

In view of the comprehensive nature of many medical care plans and of the vast sums expended, it has always seemed to me ironical that few States employ medical directors. In addition to the 2 health officers who direct the medical assistance program, only 11 States employ physicians to administer the medical care program. And this in agencies which employ a supervisory ophthalmologist to determine blindness and physiatrists and internists to determine disability! Moreover, I am told, that in many States, the excellent diagnostic information secured to determine eligibility is put to no further use. Medical services purchased are usually remedial-rarely are preventive or restorative services purchased. Thus, we are increasing the number of disabled who will continue to require large sums for their support, including their medical care.

Fortunately, some communities have begun to look for ways in which early diagnosis and treatment services can prevent disabling illness, and at other projects designed to restore the disabled to self-care. Hopefully, the 1956 amendments to the Social Security Act, stressing self-help and self-care, will motivate many agencies to undertake such projects. Iet me give you a few examples of demonstrations in California and New Jersey that have proved most successful.

In Santa Cruz County, Calif., the local health department offers a physical screening and treatment program to all old-age assistance recipients who wish to enroll in the program. Costs are met through a combination of ingenious financial arrangements. The welfare department considers the physical screening phase a part of its determination of need and for this reimburses the health department from its administrative fund, thus securing half the cost from Federal funds. The State's medical care 
program meets the costs of home and office visits and some drugs. Surgery, drugs not provided through the State program, and dental and ancillary services are financed by local health department funds. This program which has been operating since September 1955 has served 1,501 recipients or nearly one-half the total old-age assistance caseload in the county. Three clinic sessions are held weekly. A distinguished retired physician who serves without compensation conducts the history and physical examination. A public health dentist, public health nurse, and social worker are provided by the health department.

In a paper recently presented to the State directors of chronic disease programs, Dr. Russell S. Ferguson, health officer of Santa Cruz County, described the program in detail pointing out the financial savings as well as the better health which resulted from prompt identification of medical need and a team approach to developing a treatment plan. $\mathrm{He}$ concludes that important results have been achieved through this project:

"First, an increased interest by the individual with respect to the future maintenance of his own health achieved by the screening examination and the immediate reference to the physician of his choice. Second, through our mobilization of every financial and community resource we have been able to provide the vendor of medical, dental, and ancillary services and the recipient with means whereby the latter's health may be maintained. Third, we have been able to restore these people to the dignity of private patients in private hospitals for surgical care resulting in impressive savings to the county and restoring to the surgeon his privileged relationship with the patient. Finally, we are convinced that these services can be provided at exceedingly low cost and do contribute to the prevention of long-term illness involving institutional care and the prevention of blindness" (4).

Within New Jersey, following the mandate of the Prevention of Chronic Illness Act, a project was designed in 1955 to make restorative services available to selected persons receiving public assistance. Many of you probably know of the restorative services unit of the Essex County Hospital in Belleville. It was financed by a combination of State health and county welfare funds and with joint planning by official bodies, seven community hospitals, and the Essex County Medical Society. The focus of this project was on restoration of chronically ill and aged individuals to self-care.

Many of the patients had a long history of hospitalization and most were bedfast or chairborne. Of the 188 admissions to the project, 143 outlived the study period. Of these, 75 percent were bedfast on admission, but only 3 percent were bedfast on discharge. The study documents the savings in dollars, in use of expensive medical facilities, and last but not least in human dignity and self-sufficiency. A report of the study presented before the 1958 annual meeting of the American Public Health Association was prepared by Adriane V. Duffy in collaboration with Marguerite F. Hall. Following the pattern established at Essex County Hospital, this type of professional, technical, and financial assistance is being extended by the State health department to other community hospitals in order that restorative services may be provided as soon as possible after the onset of illness. Such measures are designed to prevent disabling impairments and to minimize the disruption of family life.

Both of the projects described illustrate new trends in public health administration that should be of as much interest to welfare departments as are the recent amendments to the public assistance titles of the Social Security Act concerning matching of expenditures for medical care. The latter made more Federal money available to State agencies and also made possible simplifications in the purchase of medical services for public assistance recipients. They did not-and were not devised-to assure the availability of the highly specialized preventive and restorative services needed by these recipients. More and more, the role of public health departments is being shaped to include this important responsibility. The Santa Cruz and Belleville demonstrations, hopefully, will stimulate other county health and welfare departments to combine resources to get preventive health services to recipients at an early date.

New Jersey is the only State in the Union which has set out to make homemaker service 


\section{Recommendations}

The following summarizes the Report and Recommendations of the New Jersey Commission to Study the Administration of Public Medical Care. The publication is available from the New Jersey State Department of Institutions and Agencies.

"Organized medical care in the widest sense' of the word has come to be recognized as essential to the effective and economical operation of the public assistance system as well as to the welfare of needy persons. There is hardly a more fascinating chapter in the history of social organization of medical care in this country than the story of the progress from repression of pauperism to rehabilitation of the recipient of public aid; from provision of some medical treatment and minimal custodial care to that of a wide range of protective, curative and rehabilitative health services; and from reluctant acceptance of paupers to eligibility of all persons receiving basic income maintenance and increasingly of medically needy people," Dr. Franz Goldmann stated in his book "Public Medical Care" (1945).

The commission believes that it is in the spirit of this statement by Dr. Goldmann that the medical care program for all the needy of the State should be organized and administered. They believe that there is a base on which a good program can be developed but that some realinement is necessary both in administration and financing.

The commission believes the duplication of administration by multitudinous agencies should be abandoned and that the county welfare boards administering the four categories of aid could best be developed as the units to administer all the medical care programs for the needy as well as the medically indigent.

Well-organized comprehensive medical care programs require the advice and counsel of trained medical practitioners who should be assisted by the services of professional medical social workers and other consultants in the allied disciplines representing dentistry, optometry, hospital management, nursing, and others. The medical unit should have the services of technicians to implement special studies.

There should be communication with the professional organizations representing the suppliers of medical, hospital, and allied services through desig- nated members serving on committees consulting with the professional personnel of the agency.

A comprehensive program should include the gamut of medical, hospital, and allied services any or all of which may be necessary to care for the needs of the recipients. The individual or institution providing the services should be paid directly on a fee-for-service based on a negotiated fee schedule. Hospital rates should be established on the basis of a reimbursable cost formula acceptable to the department and the hospital association.

The present lump-sum appropriation system for voluntary hospitals and nursing organizations should be abandoned as administratively unsound and economically indefensible.

Those persons who are ordinarily self-supporting, but because of illness become medically indigent, should be the responsibility of the county welfare boards on the basis of established criterion of need. This criterion should be established by the board of control of the department of institutions and agencies.

The obligation to repay the agency for medical expenditures should be established for the general assistance recipients and the medically indigent by rule of the department. This obligation should take into consideration the individual's particular circumstance and the burden of high cost medical care, particularly hospitalization.

Financing of hospital care for all those persons who are in need should be borne more equitably by the Federal, State, and county governments. The municipalities will be participating by their contributions to the county tax funds.

The commission believes that a medical care program for those in need and the medically indigent in which the executive officer, the legislature, and the people of New Jersey can take pride is the objective of this study. The program should have a sound legal base and good professional administration so that it fulfills the purpose of serving those in need in a wise and humanitarian spirit.

The success of the program will be determined by the interest and competence of those who have the responsibility for the administration of medical care for those who cannot provide it for themselves. 
available to everyone who needs it, and the goal is more than half reached. Now 14 agencies offer homemaker service in 13 counties. Three other counties are working toward establishment of a program. This is another instance in which the health department has undertaken to create the availability of services and in which public welfare participates actively both in plamning and in financing the service.

When communicable diseases were the major focus of public health programs, a battery of laboratory, diagnostic, and treatment services were made available to help practicing physicians give good care to their patients. So today when chronic disease is the major public health problem, health departments are developing new techniques of therapy and new methods of organizing health services so that they can offer to the practicing physician the services of public health nursing, medical social work, physical therapy, and occupational therapy which, when coordinated under the physician's direction, will bring long-term patients the kind of care that meets their needs.

\section{Guidelines}

To help public welfare agencies arrive at some simple "do's" and "don'ts" in undertaking the very important task which is laid out by the commission's report, let me summarize a few of the "do's":

- Consolidate your local efforts into units of workable size. It is folly to think of 500 local medical plans in the State; 21 is a reasonable number.

- Appoint in each county one or more advisory committees to help develop the county adaptation that will meet the requirements of the State plan and make best use of the local resources. Choose the public-spirited leaders from medicine, dentistry, nursing, social work, and other health interests to help you. Hospital and nursing home administrators and directors of visiting nurse associations are logical candidates for membership. In my judgment, the health officer or his representative is a "must" on such a committee. To balance the health interests, it is well to include representation from industry and labor and the lay public.
- Employ a good medical director, full time wherever practical. In selecting him, do not overlook the physician who has had administrative experience in industry, in group practice, or in the military service.

- Look to the medical society for guidance. Their help is a sine qua non in designing and carrying out practical policies and procedures. At the outset take to them your little problems as well as the big ones so they can know of your failures as well as successes. This will assure that their interpretation of the program to their fellows and to the other purveyors of health services is a true reflection of what the agency means to do and why and how it does so.

- Make a plan for seeing the official publications of national agencies that can keep you abreast of developments in medical care. The journals of the American Dental Association, American Hospital Association, American Medical Association, American Nursing Home Association, American Public Health Association, and the American Public Welfare Association all carry articles of value to administrators of public welfare medical care programs. The same is true of the Social Security Bulletin and the Public Health Service's Public Health Reports. Two less technical publications which the American Medical Association publishes for free distribution have real value for you-The AMA News and the Chronic Illness News Letter. Shortly, the AMA will begin publication of a Bulletin on Homemaker Services.

The American Public Welfare Association has a series of publications specific to the administration of public welfare medical care programs, "The Physician in the Public Welfare Agency," "The Medical Social Worker in the Public Welfare Agency," "Self-Evaluation Schedule for Medical Assistance Programs," "Improving the Quality of Tax-Supported Medical Care," and "Medical Care in Public Welfare" (report of Institute III), to mention only a few. All of these are for sale by the association at a modest price.

- Plan for at least an annual meeting where medical directors can share their experiences. A group council such as the New Jersey Welfare Council provides a readymade vehicle for such sessions.

- Encourage your medical directors to at- 
tend regional meetings of the American Public Welfare Association and the biennial roundtable so they can talk with their counterparts in other States.

There are a few cautions I should like to advance in the "don't" column:

- Don't regard the medical assistance program as merely a purchase-of-service program. It is much more than that. Be concerned with health maintenance and health promotion. Give serious consideration to the evaluation of present services and redirection when indicated. Make use of diagnostic records to plan with recipients for the treatment they need.

- Don't allow the costs of hospital and nursing home care to cloud your vision. In my judgment, preoccupation with these two types of service prevails throughout the entire United States in spite of the fact that most people who are ill or disabled are at home and prefer to be cared for there. Give services for patients at home a high priority.

- Don't work in isolation. Especially learn the differences in philosophy and objective of other official agencies like the health or rehabilitation departments and develop a systematic method of cooperation with them.
- And, finally, don't be discouraged. You are on the eve of one of the most exciting tasks you will ever have. I once organized a local medical care program with the active help of all the organizations I have mentioned. It took about 9 months to develop basic policy and procedure. They were the most rewarding months of my life. I had more help from more people than in any corresponding period of my 35 years of work. I wish you the same good fortune.

\section{REFERENCES}

(1) New Jersey Commission to Study the Administration of Public Medical Care: Report and recommendations. Trenton, September 1959, 62 pp.

(2) Social Security Bulletin 22: 36 (table 15), June 1959.

(.3) Perrott, G. St.J.: Medical care under Federal emergency relief. A 1934 report issued in view of recently enacted provisions for medical care of the needy. U.S. Public Health Service, December 1950, 101 pp. (Mimeographed.)

(4) Ferguson, R. S.: The Santa Cruz geriatric program, 1959. Presented at the State and 'Territorial Chronic Disease Directors' Meeting, Chicago, September 21-23, 1959, 6 pp. (Mimeographed.)

\section{Community Health Administration Studies}

During the past several years, the W. K. Kellogg Foundation has a warded grants to three State health departments (California, Florida, and Washington) and to the schools of public health of three universities (Johns Hopkins, Michigan, and Toronto) for derelopment of studies in community health administration. From these studies the Foundation hopes will emerge new relationships and patterns of public health practice for both the schools and the operating agencies.

Directors of the studies held their first meeting in Washington, D.C., on March 17 and 18, 1960. The meeting was sponsored by the Foundation to provide an opportunity for exchange of viewpoints and experience and to discuss common problems. H. H. Hasson, associate director of the division of medicine and public health of the Foundation, requested Dr. William F. Mayes, assistant chief, Division of General Health Services, Public Health Service, to assist him in planning the meeting and to serve as its chairman. 